\title{
JUSTIÇA RESTAURATIVA E PODER JUDICIÁRIO: PERSPECTIVAS E IMPASSES NA APLICAÇÃO DE PRÁTICAS RESTAURATIVAS PELA JUSTIÇA TRADICIONAL
}

\section{RESTAURATIVE JUSTICE AND JUDICIARY POWER: PERSPECTIVES AND IMPASSES IN THE APPLICATION OF RESTORATIVE PRACTICES BY TRADITIONAL JUSTICE}

Gabriel Maravieski*

\section{RESUMO}

O presente artigo tem o escopo de abordar, brevemente, a questão da dificuldade de se conceituar a justiça restaurativa, ante as diversas possibilidades de sua aplicação, considerando ainda ser necessário que, em cada lugar em que se aplique, a prática restaurativa observe o seu entorno, para se definir e conceituar. Em um curto espaço, se expôs a noção do que seria, bem como se introduziu algumas normativas da justiça restaurativa, a nível nacional, e, posteriormente, em uma visão micro, a nível de Estado do Paraná. Na sequência, o que se intentou foi apresentar um panorama breve sobre as vantagens e os impasses da aplicação da justiça restaurativa pelo Poder Judiciário. Buscou demonstrar de que forma pode haver uma colonização das práticas restaurativas pelo sistema de justiça criminal comum, sob o risco de engessar e aplacar os potenciais da justiça restaurativa.

Palavras-chave: Justiça Restaurativa, poder judiciário, justiça tradicional.

\section{ABSTRACT}

This article aims to briefly address the issue of the difficulty of conceptualizing restorative justice, given the various possibilities of its application, considering that it is also necessary that, in each place where it is applied, the restorative practice observes its environment, to define and conceptualize. In a short space, the notion of what would be was exposed, as well as some norms of restorative justice were introduced, at the national level, and, later, in a micro vision, at the Paraná State level. Next, what was intended was to present a brief overview of the advantages and impasses of the application of restorative justice by the Judiciary. It sought to demonstrate how there can be a colonization of restorative practices by the common criminal justice system, at the risk of styling and appeasing the potentials of restorative justice.

Keyswords: Restorative Justice, judiciary, traditional justice.

"Mestre em Direito (Unibrasil - 2020). Especialista em Direitos Humanos e Realidades Regionais (UNICESUMAR - 2018) e em Direito Ambiental (UNINTER - 2016). Graduado em Direito (CESCAGE - 2013) 


\section{INTRODUÇÃO}

$\mathrm{Na}$ crise em que se encontra o sistema de justiça penal brasileiro, aqui tratado em sentido amplo - desde o momento da tomada de conhecimento, por parte do Estado e seus órgãos, da ocorrência de uma conduta desviante, até o momento em que se executa a sanção penal imposta unilateralmente -, a busca por alternativas é medida necessária.

No arcabouço de possibilidades (nem tão extenso), a justiça restaurativa toma lugar de proeminência como alternativa possível, seja de desafogamento de um sistema colapsado e inchado, seja de promoção da paz social, também um fim esperado pela atuação do Estado na seara penal.

Nesse cenário, de busca por modelos alternativos, se deve ter em mente, para além da ideia de aplicação de novos paradigmas, a necessidade de se tratar a realidade como ela é. Ou seja, a necessidade de se focalizar que, em se tratando de Brasil, se está a tratar de América do Sul, sul do mundo, região peculiar e com características próprias.

Aqui reside o cuidado que se deve ter ao tratar de tema tão sensível quanto são as práticas restaurativas.

Para se chegar a um resultado satisfatório, não se é recomendável importar modelos prontos e acabados, sem considerar as nuances que envolvem a vida e os sentimentos de cada envolvido em condutas que se desviam do que foi estabelecido como normal.

O anormal encontra normalidade dentro do seu próprio meio. E é essa normalidade que deve ser entendida, para então se chegar a uma proposta suficientemente garantidora de resultados, que promova o bem-estar, a paz e a construção de uma sociedade mais justa e igualitária.

O presente trabalho pretende apresentar, em curto aparato, o perigo que pode haver ao se aplicar práticas restaurativas pelo poder institucionalizado, importando-se práticas que, ao darem certo em outros lugares, podem não ser tão bem recebidas em nosso meio social.

Em um primeiro tópico se apresentará um panorama da justiça restaurativa, seus princípios e premissas estipulados para sua exteriorização em nosso país. Nesse ponto se destacam as normativas até então existentes sobre a matéria, não em sua totalidade, mas em especial aquelas de maior relevância.

Ainda nesse tópico se tratará de observar a normatividade nacional da justiça restaurativa, bem como se demonstrará sua normatização a nível de Estado do Paraná, como um exemplo de micro visão.

No segundo tópico, se discorre sobre a questão da aplicação da justiça restaurativa pelo Poder Judiciário. Em que aspecto isso pode ser considerado positivo, e em qual viés há uma prospecção negativa nessa atuação judiciária.

Para tanto, se observa e analisa em que sentido há um plus positivo nessa aplicabilidade judicial da justiça restaurativa, considerando a confiança depositada pela população no Poder Judiciário.

Por outro lado, um viés negativo, que é justamente o perigo de se refletir, nas práticas restaurativas que, por vocação, devem ser abertas a formas dialógicas e não engessadas, o formalismo e a solenidade dos processos judiciais, cheios de meandros que, ao invés de aproximar o jurisdicionado interessado, muitas vezes o exclui do cenário judicial.

À guisa de conclusão, sem pretensão de se chegar a uma definição, mas sim com intuito de lançar pontos ainda carentes de análise, serão sopesadas as ideias apresentadas no corpo do trabalho.

Para tanto, se utilizou do método de revisão bibliográfica, com busca em autores que reflitam o espírito da justiça restaurativa, em se tratando de Brasil ou do estrangeiro. 
Praticar a restauração é tarefa da justiça restaurativa, não sem método, não sem fundamento, mas com olhos de quem pretende alterar a realidade, passo a passo, em busca de um futuro mais promissor.

\section{JUSTIÇA RESTAURATIVA OU PRÁTICAS RESTAURATIVAS: CONCEITUAÇÃO E NORMATIZAÇÃO NO BRASIL}

O sistema de justiça penal, ou criminal, e seus procedimentos e consequências podem ser vistos sob a ótica de duas lentes, de acordo com Howard Zehr (2008, p. 185).

De um lado temos a lente retributiva, que, em uma descrição simplista, mas que situe o leitor, nos faz enxergar que há necessidade de se retribuir o mal pelo mal. Ou seja, se cometido um crime, necessária uma atuação estatal que represente uma retribuição para aquele mal causado.

Noutro giro, temos à disposição a lente restaurativa, que busca enfrentar o problema e trazer soluções que integrem os envolvidos, promovendo uma reconciliação ou reaproximação, objetivando um consenso para se alcançar a paz e eventual reparação do dano, não necessariamente pelo viés prisional.

Para Howard Zehr (2008, p. 185), portanto, as duas lentes podem ser assim definidas:

Justiça retributiva

O crime é uma violação contra o Estado, definida pela desobediência à lei e pela culpa. A justiça determina a culpa e inflige dor no contexto de uma disputa entre ofensor e Estado, regida por regras sistemáticas.

Justiça restaurativa

O crime é uma violação de pessoas e relacionamentos. Ele cria a obrigação de corrigir os erros. A justiça envolve a vítima, o ofensor e a comunidade na busca de soluções que promovam reparação, reconciliação e segurança.

Se pode dizer que a conceituação acima parte daquele que, chamado "avô da justiça restaurativa", conforme consta na orelha de seu livro "Justiça Restaurativa" (ZEHR, 2015), apresentou a ideia de uma justiça restaurativa para nosso tempo.

O termo 'justiça restaurativa' não encontra consenso, perante os que o estudam, no sentido de ter delimitada sua origem e sua sistematização.

Por um lado, isso se dá pelo fato de que esta justiça, se assim chamada, "não está orientada por uma conceituação única ou consensual" (KONZEN, 2007, p. 78). O motivo para isso é que, a depender do local, a justiça restaurativa vai precisar de conceituação própria e princípios peculiares, considerando o contexto social de determinada comunidade, ao tratar de seus problemas conflituais.

Vilobaldo Cardoso Neto (2018, p. 97), ao explicitar a visão de justiça restaurativa trazida por Afonso Armando Konzen, nos remete ao fato de que esse último vê na justiça restaurativa uma capacidade tal de flexibilizar-se, para ajustar-se às necessidades de determinada realidade e dos interessados em certo fato.

Tanto é difícil conceituar a justiça restaurativa, que, de acordo com Cristina Rego de Oliveira (2013, p. 56-57)

[...] os críticos a abordam como um conceito aberto - unfinished product - variando sua caracterização de acordo com seus valores, princípios e ainda diante dos resultados pretendidos, evitando, desde logo, uma visão reducionista do conceito e flexibilizando-o de modo a permitir "a sua melhor adaptação a diferentes cenários sociais". 
Em que pese essa difícil conceituação, em virtude da necessidade de se avaliar, em conjunto, o local em que as práticas estão inseridas, não se tem obliterado o esforço de diversos autores em identificar um ponto comum de origem para as práticas restaurativas.

Nesse seguimento, há posicionamento de que a justiça restaurativa, como vem sendo concebida e construída, passa originalmente pelos modos de fazer justiça aborígenes e de comunidades tribais, fincadas no território da Austrália, Canadá e Finlândia (OLIVEIRA, 2013, p. 58).

Portanto, a justiça restaurativa muito tem de aproximação e germinação a partir de práticas comunitárias e, de certa forma, desvinculadas do poder instituído, da forma tradicional de se fazer justiça.

Neste ponto, alerta Cristina Rego de Oliveira (2018, p. 59), que se deve atentar

[...] para o fato de que as práticas restaurativas não são uma forma primitiva de realização de justiça, nem mesmo se equivalem à justiça pública "oficial", visto que pressupõem um modelo consensual de resolução de controvérsias, numa perspectiva "menos punitiva, mais equilibrada e humana". Isso porque, o crime deixa de ser concebido enquanto ofensa a um bem jurídico pelo desatendimento de uma norma abstratamente veiculada (ou seja, enquanto infração estatal decorrente de violação da lei), para traduzir-se numa ruptura do relacionamento entre os sujeitos.

Com isso, se pode dizer que a justiça restaurativa é um método de solução pacífico de conflitos, atuando como auxílio ao acesso a uma ordem jurídica justa, auxiliando no papel já delegado ao poder judicial formal (ORSINI e LARA, 2013, p. 305).

Na visão de Philip Oxhorn e Catherine Slakmon (2005, p. 12), a justiça restaurativa pode ser enquadrada enquanto um sistema de micro-justiça. Ou seja, para os autores, quando a justiça formal e instituída falha na entrega da prestação efetiva, os cidadãos buscam formas ilegais de se fazer o justo. Nesse cenário surgem as micro-justiças, que podem ser encaradas como sistemas à parte do tradicional, e que se contrapõem às formas ilegais de se fazer justiça, embora não advenham do Estado. Nesses modelos se encontram as práticas restaurativas.

Vê-se que para os autores a "justiça" restaurativa, é na realidade um conjunto de práticas, que proporcionam uma noção de justiça aos cidadãos. Dentro das micro-justiças, as práticas restaurativas representam um modo regular de se fazer justiça fora do sistema imperante.

Desta maneira, a conceituação da justiça restaurativa deve considerar, de qualquer forma, o local onde suas práticas estão sendo postas, o que afasta a existência de um conceito fechado e imutável.

Portanto, é com esse intento que se passará a expor o que há de normatizado no Brasil sobre o tema, primeiro sobre uma visão macro (nacional), para depois passar a uma visão exemplificativa micro (Estado do Paraná).

Em sede nacional, a justiça restaurativa encontrou um documento de importância primeva na Resolução n 125/2010 do Conselho Nacional de Justiça (CNJ), que trata da política judiciária nacional para tratamento adequado dos conflitos de interesses, no âmbito do Poder Judiciário brasileiro.

A importância da resolução reside no fato de ter previsto, em seu art. $7^{\circ}$, a criação de Núcleos Permanentes de Métodos Consensuais de Solução de Conflitos (NUPEMEC). 
Para Vilobaldo Cardoso Neto (2018, p. 161)

[...] a Resolução $\mathrm{n}^{\circ} 125$ do CNJ tem papel fundamental na implementação da Justiça Restaurativa no âmbito judicial brasileiro, pois define critérios básicos para o estabelecimento de NUPEMECs pelos Tribunais dos Estados, e, a partir da criação destes, possibilita que as práticas restaurativas possam ali ser desenvolvidas.

Posteriormente, após esse aparato inicial que desenhou um plano profícuo para a disseminação e implementação de práticas restaurativas em cenário nacional, foi editada a Resolução n 225/2016, também do Conselho Nacional de Justiça.

Essa resolução, agora sim, trata especificamente da justiça restaurativa, e sistematiza sua aplicação e seus regramentos básicos em âmbito nacional.

É da citada resolução no 225/2016 que se extrai, em se tratando de Brasil, um conceito, ao menos uma tentativa de conceituação, da justiça restaurativa. Dispõe o art. $1^{\text {o: }}$ :

Art. $1^{\circ}$. A Justiça Restaurativa constitui-se como um conjunto ordenado e sistêmico de princípios, métodos, técnicas e atividades próprias, que visa à conscientização sobre os fatores relacionais, institucionais e sociais motivadores de conflitos e violência, e por meio do qual os conflitos que geram dano, concreto ou abstrato, são solucionados de modo estruturado na seguinte forma:

I - é necessária a participação do ofensor, e, quando houver, da vítima, bem como, das suas famílias e dos demais envolvidos no fato danoso, com a presença dos representantes da comunidade direta ou indiretamente atingida pelo fato e de um ou mais facilitadores restaurativos; II - as práticas restaurativas serão coordenadas por facilitadores restaurativos capacitados em técnicas autocompositivas e consensuais de solução de conflitos próprias da Justiça Restaurativa, podendo ser servidor do tribunal, agente público, voluntário ou indicado por entidades parceiras;

III - as práticas restaurativas terão como foco a satisfação das necessidades de todos os envolvidos, a responsabilização ativa daqueles que contribuíram direta ou indiretamente para a ocorrência do fato danoso e o empoderamento da comunidade, destacando a necessidade da reparação do dano e da recomposição do tecido social rompido pelo conflito e as suas implicações para o futuro.

Se vê, portanto, que a tratativa que se deu à justiça restaurativa, nacionalmente, é de um "conjunto ordenado e sistêmico de princípios, métodos, técnicas e atividades próprias". Dessa forma, se pode dizer que não se trata de um único viés, mas sim um conjunto de fatores que devem, conjuntamente, ser considerados, para se chegar à solução pacífica de um determinado conflito. Isso corrobora o que antes exposto, que cada realidade possuirá sua própria justiça restaurativa.

Em uma guinada de direção, ao se falar de Estado do Paraná, a aplicação e normatização da justiça restaurativa é proeminente função do Poder Judiciário.

Em 2014 foi estabelecida a Comissão Paranaense de Práticas Restaurativas do Tribunal de Justiça do Paraná, através da Portaria nº 11/2014 do NUPEMEC. Essa comissão teve como escopo deliberar sobre práticas restaurativas no âmbito do Poder Judiciário estadual (BAELLAR, GOMES, MUNIZ, 2016, p. 328).

No mesmo ano foi realizado, em âmbito estadual, na cidade de Ponta Grossa/PR, o I Encontro de Práticas Restaurativas. Em 2015, audiências públicas foram realizadas na Assembleia Legislativa do Paraná, na Câmara Municipal de Ponta Grossa/PR e na Câmara Municipal de Londrina/PR. Essas audiências públicas resultaram em debates que orientaram a formulação da Resolução $\mathrm{n}^{\circ}$ 
4/2015-NUPEMEC, e do Manual de Justiça Restaurativa, anexo à Resolução (BACELLAR; GOMES; MUNIZ, 2016, p. 329-330).

A resolução $n^{\circ} 4 / 2015$ do NUPEMEC, em seu art. $1^{\circ}$, não prevê o afastamento da justiça comum para a aplicação de práticas restaurativas, dando ênfase à aplicação da restauratividade pelos Centros Judiciários de Solução de Conflitos e Cidadania (CEJUSC).

Outro documento oriundo do Poder Judiciário estadual do Paraná, é o Manual de Justiça Restaurativa. No documento se encontra uma possível definição para justiça restaurativa, dizendo ser "um procedimento que prioriza o diálogo entre os envolvidos na relação conflituosa e terceiros atingidos, para que construam de forma conjunta e voluntária a soluções mais adequadas para a resolução dos conflitos".

Portanto, se vê que, a nível estadual, em se falando de Paraná, a justiça restaurativa é encarada como um procedimento de diálogo, que propicia às partes envolvidas a possibilidade de chegar a um consenso sobre a relação conflituosa, sempre de forma dialógica.

Pelos cenários acima expostos, pode se concluir que a construção de um conceito sobre justiça restaurativa não é algo próximo de acontecer, dada a multiplicidade de fatores a serem observados em cada etapa e localidade de aplicação.

Também se questiona se é desejável que essa conceituação seja consenso a nível de Brasil, haja vista a pluralidade existente em país continental, que revela diversas nuances sociais e problemas muito peculiares, para os quais somente determinada parcela populacional pode ter a resposta satisfatória.

O que se deve considerar, também, é a questão de determinados elementos que a justiça restaurativa deve focalizar em sua atuação, seja em que projeto for.

Isso porque a justiça restaurativa tem uma função plurifocal de justiça, ou seja, engloba os diversos envolvidos no conflito e garante, também, maior participação democrática no processo decisório, inclusive dos órgãos oficiais de poder.

Segundo Raquel Tiveron (2017, posição 2244)

A justiça restaurativa atende a esta necessidade plurifocal de justiça, já anunciada por Fraser e Honneth, por tratar também de cidadania, do reconhecimento da vitima e do ofensor como atores decisórios, além das preocupações tradicionais de justiça destacadas pela teoria crítica, como a reintegração social do ofensor, a seletividade do sistema de justiça, a igualdade de direitos, de liberdade e de oportunidades. Esta plasticidade lhe possibilita aumentar o grau democrático nas decisões finais, à medida que a justiça restaurativa congrega todos os afetados interagindo na construção de um desfecho para o crime em condições paritárias de expressão e comunicação.

Assim, o que se busca com a justiça restaurativa, ainda que não haja um conceito estabelecido e fechado, é a integração dos diversos atores do sistema criminal, inclusive, com os diretamente afetados, para se chegar a uma forma mais democrática de decisionismo, afastando as decisões unilaterais e de cima para baixo. 


\section{JUSTIÇA RESTAURATIVA E PODER JUDICIÁRIO: VANTAGENS E IMPASSES DA APLICAÇÃO DE PRÁTICAS RESTAURATIVAS PELO PODER JUDICIÁRIO}

Ao se tratar de justiça restaurativa, mormente em se falando de Brasil, há proeminência para as práticas incentivadas e exteriorizadas pelo próprio Poder Judiciárioº.

Em um primeiro momento, apresentar uma ideia de justiça restaurativa fora do âmbito do Poder Judiciário pode soar estranho, por se tratar do poder estatal incumbido de prestar a jurisdição. Contudo, há pontos positivos e também negativos nesse cenário.

Por um lado, há uma confiança da população no Poder Judiciário, representando um grau de 52\% da população, mais da metade, portanto, de acordo com o "Estudo da imagem do judiciário brasileiro", realizado pela Fundação Getúlio Vargas, sob encomenda da Associação dos Magistrados Brasileiros (FGV, 2019, p. 7).

Esse número reflete que é positiva a atuação do Poder Judiciário enquanto disseminador de práticas autocompositivas, no que se inclui a justiça restaurativa, porquanto a população, em sua maioria, confia nesse poder e na função por ele desempenhada.

Ainda assim, teoricamente há riscos de se promover uma captação das práticas restaurativas pelo Poder Judiciário que, via de regra, é formalista e conservador, implicando na transfiguração das práticas restaurativas em uma opção, somente, ao sistema de justiça formal, tratando-a como um apêndice dentro de uma divisão de competências (GIAMBERARDINO, 2014, p. 174).

Ou seja, a aplicação da justiça restaurativa pelo Poder Judiciário pode transforma-la em mera opção, somente mais um método para ser utilizado, não se revelando como uma alteração de paradigma, por assim dizer, dentro do sistema de justiça criminal.

Outro ponto a ser considerado, é que os atores do sistema de justiça criminal, sejam juízes, promotores ou advogados, ficam presos a um sistema normativo e a funções institucionalmente estabelecidas, não havendo muitas possibilidades de se fugir destes locais funcionais. Neste sentido, Renato Sócrates Gomes Pinto (2011, p. 25), expõe que

[...] os operadores do sistema estão vinculados a essas normas, que se expressam por princípios e regras inderrogáveis, tais como o do devido processo legal, que se não for observado, um outro princípio, ainda maior -o princípio da legalidade -estará também sendo violado, numa ruptura que o sistema responde com efetivos mecanismos de controle.

Portanto, não se olvida que há um mecanismo de controle, também próprio do sistema de justiça tradicional, sobre seus atores, que, se atuarem fora dos ditames estabelecidos, responderão por esses atos administrativamente.

Aqui mora, a nosso ver, um perigo de se atrelar a prática restaurativa aos próprios Tribunais, porquanto a margem de discricionariedade para atuação em programas não convencionais é pequena, o que pode representar um engessamento da justiça restaurativa.

\footnotetext{
'Veja-se, v.g., as seguintes notícias: justiça restaurativa aplicada à justiça da infância e da juventude no Rio Grande do Sul (https://www.tjrs.jus.br/novo/cij/biblioteca/justica-restaurativa/); justiça restaurativa avança sendo implantada pelo Tribunal de Justiça de Santa Catarina (https://www.tjsc.jus.br/web/imprensa/-/implantacao-da-justica-restaurativa-avanca-no-poderjudiciario-de-santa-catarina?p___back_url=\%2Fpesquisa\%3Fq\%3Djusti\%25C3\%25A7a\%2Brestaurativa); justiça restaurativa na área da infância e juventude do Tribunal de Justiça do Estado de São Paulo (https://www.tjsp.jus.br/Infancia Juventude/ InfanciaJuventude/JusticaRestaurativa_Default).
} 
Por isso seria interessante a criação de programas de justiça restaurativa fora da proteção do manto da justiça tradicional, inclusive para refletir melhor a ideia de voluntariedade das partes e incentivar o diálogo.

Esse diálogo, no processo comum, não é aberto ao livre alvitre das partes, ao passo que, na justiça comum, segundo Cristina Rego de Oliveira (p. 37)

[...] os atores permanecem alheios ao desfecho do litígio: ao réu consolida-se o rótulo de outsider socialmente imputado; e à vítima, considerada em abstrato, um status de objeto legitimador da persecução penal e, portanto, necessária para reconstrução dos fatos praticados em desconformidade ao direito, para que ao final seja reafirmada a validade da norma jurídica.

O ideal, em se tratando de justiça restaurativa, ou práticas restaurativas, seria sua implementação em ambiente separado da pompa e cerimônia que, sabe-se, envolve o Poder Judiciário e seus ritos, o que, opina-se, pode vir a prejudicar o desenvolvimento de eventual programa, acuando-se as partes envolvidas.

Para Neemias Moretti Prudente e Ana Lucia Sabadell (2008, p. 52), a justiça restaurativa

[...] se trata de um processo estritamente voluntário, relativamente informal, a ter lugar, preferencialmente, em espaços comunitários, sem o peso e o ritual solene, da arquitetura do cenário Judiciário, intervindo um ou mais mediadores ou facilitadores, e podendo ser utilizado, técnicas de mediação, conciliação e transação para se alcançar o resultado restaurativo [...].

Conforme se vê, é importante que a prática restaurativa se dê, preferencialmente, e não obrigatoriamente, fora dos espaços solenes e ritos formais do Poder Judiciário.

Não se tira de mente a importância do Poder Judiciário em implementar boas práticas de resolução de conflitos, conforme exposto anteriormente, diante da confiança da população, em sua maioria, nesse poder estatal.

Contudo, para que se chegue a um potencial programa restaurativo, o ideal seria implementar práticas fora do judiciário, em ambiente onde as partes se sintam mais familiarizadas e à vontade, tanto para expor seus problemas, como para ouvir o outro, em exercício autêntico de alteridade.

No entanto, já estando sendo disseminada a justiça restaurativa pelos próprios tribunais estaduais, se deve ter em mente que, para que a ideia de justiça restaurativa seja possível de se concretizar no sistema criminal brasileiro, é necessário, sobretudo, a mudança de pensamento dos atores principais do sistema.

Repensar a cultura jurídica é necessário, para se evitar que haja colonização de práticas inovadoras, não se permitindo que haja um aplacamento do potencial da justiça restaurativa (ACHUTTI, 2016, posição 1986).

Nesse seguimento se pode dizer que a dificuldade para implementação de práticas restaurativas de forma isenta, "remetem não à tradicional falta de vontade política ou a dificuldades externas, mas a modos de pensamento que expulsam tudo aquilo que puder causar algum problema ao modelo de justiça criminal concebido" (ACHUTTI, 2016, posição 2022/2028).

Veja-se que um caminho para se chegar a uma maior vontade dos atores judiciários (e aqui leia-se juízes, promotores, advogados e defensores públicos), passa pela qualificação do seu pessoal, com capacitações constantes e consciência da interdisciplinaridade que deve nortear a matéria restaurativa. 
Há ainda a ideia arraigada de que os juízes precisam resolver os problemas, e que estão escravos da lei, não podendo inovar no seu atuar, sob pena de desconfigurar sua função.

Isso reflete e deixa transparecer, segundo Daniel Achutti (2016, posição 2209),

[...] sintomas de um sistema de justiça que privilegia antes a resolução administrativa dos processos judiciais do que a resolução satisfatória de cada caso, conforme as expectativas das partes envolvidas. A preocupação central com questões técnico-burocráticas se sobrepõe ao conteúdo efetivo de cada processo e esconde, entre folhas, carimbos e certidões, o verdadeiro motivo da existência de uma ação judicial: um conflito envolvendo pessoas reais.

Portanto, do que se expôs, se pode dizer que um perigo latente na aplicação desmedida de práticas restaurativas pelo Poder Judiciário é o de haver uma colonização de suas práticas.

Essa colonização pode se dar com a importação de ritos e métodos que tornem inócua a atuação dos atores restaurativos, afundando em um emaranhado burocrático aqueles que pretendem solver seus conflitos de forma dialógica e sem interferência de terceiros que, por mais que tentem, não saberão exteriorizar os sentimentos envolvidos.

Portanto, repisa-se a necessidade de se atentar ao fato de como vem sendo desenvolvida a justiça restaurativa, em se tratando de Brasil.

Isso para se manter uma interdisciplinaridade, para que as diversas áreas do conhecimento se comuniquem e possam contribuir para a pacificação social, com o aprimoramento contínuo dos atores da justiça comum.

\section{CONCLUSÃO}

A justiça restaurativa, para além de uma teoria, deve ser encarada como um conjunto de práticas, muito mais nesse sentido.

Conforme exposto no trabalho, sua conceituação não é matéria fácil e que representa unanimidade, mas é algo continuamente em construção, com alterações substanciais a depender de onde se está falando e de onde se está praticando.

Inobstante, é importante ter em mente que a justiça restaurativa deve primar por uma resolução pacífica dos conflitos, com envolvimento das partes interessadas de maneira ativa, primando o diálogo e o consenso como meio para se atingir o fim esperado, o de curar o que, de certa forma, foi quebrado.

Nesse passo, não se pode esquecer que as práticas restaurativas não são recomendadas em cenários solenes e ritualísticos, como é o lugar do Poder Judiciário.

Não há maiores problemas, ao menos inicialmente, no incentivo e implemento de práticas restaurativas pelo Poder Judiciário, contudo, desde que se observe que não se trata de um modo de aplicação da justiça como corriqueiramente é feito pelos juízes.

Não há espaço, na justiça restaurativa, para decisões advindas de cima para baixo, mesmo que travestidas em superficiais normatizações. A liberdade e voluntariedade das pessoas envolvidas em um conflito, e que se propõem a alçar debates restaurativos, devem vir em primeiro lugar, sem interferência externa que não seja a de garantir o mínimo de urbanidade. 
Dessa forma, se estará diante de um cenário favorável para a pacificação social, muitas vezes com resultados mais vantajosos do que aqueles aplicados pela justiça comum, onde há um silenciamento das partes envolvidas, relegando-se aos terceiros não envolvidos a solução que "melhor" se aplicaria ao caso.

Portanto, após o discorrer do trabalho, não há conclusão fixa, para fins de dizer se há ou não problemas graves na aplicação da justiça restaurativa pelo Poder Judiciário. O que se pretendeu foi indicar pontos que merecem aprofundamento teórico e pesquisas consistentes, haja vista a crescente difusão das práticas restaurativas pelos tribunais.

De tudo, o que se toma por certo é que, de algum lugar, a justiça restaurativa precisa arranjar impulso, para alçar voos maiores e que abranjam os que necessitam da cultura da paz.

Se esse impulso virá do Poder Judiciário não se pode dizer ao certo, mas pelo que a pesquisa indica, as chances de isso acontecer são várias. O que se deve atentar é para o fato de não haver colonização desmedida das práticas restaurativas, sempre com vistas à interdisciplinaridade e para a desnecessidade de imposição de vontades, prevalecendo o diálogo e a construção conjunta da solução mais adequada aos conflitos sociais.

\section{REFERÊNCIAS}

ACHUTTI, Daniel Silva. Justiça restaurativa e abolicionismo penal: contribuições para um novo modelo de administração de conflitos no Brasil. - 2. ed. - São Paulo: Saraiva, 2016. E-book.

CARDOSO NETO, Vilobaldo. Justiça restaurativa no Brasil: potencialidades e impasses. - 1. ed. - Rio de Janeiro: Revan, 2018.

FUNDAÇÃO GETÚLIO VARGAS. Estudo da imagem do judiciário brasileiro. 2019. Disponível em: https://www.conjur.com.br/dl/estudo-imagem-judiciario-brasileiro.pdf. Acesso em 29 jun 2021

GIAMBERARDINO, André Ribeiro. Um modelo restaurativo de censura como limite ao discurso punitivo. 2014. 229 f. Tese (Doutorado em Direito) - Universidade Federal do Paraná, Curitiba, 2014.

OLIVEIRA, Cristina Rego de. Mediação penal e justiça: da ética da alteridade como fundamento filosófico para adoção das práticas restaurativas. - Curitiba: Juruá, 2013.

ORSINI, Adriana Goulart de Sena; LARA, Caio Augusto Souza. Dez anos de práticas restaurativas no Brasil: a afirmação da justiça restaurativa como política pública de resolução de conflitos e acesso à Justiça. Revista Responsabilidades (TJMG), Belo Horizonte, v. 2, n. 2, p. 305-324, set. 2012/fev. 2013. Disponível em https://sistemas.trt3.jus.br/bd-trt3/handle/11 103/2631 Acesso em 29 jun 2021.

OXHORN, Philip \& SLAKMON, Catherine. MicroJustiça, Desigualdade e Cidadania Democrática a Construção da Sociedade Civil Através da Justiça Restaurativa no Brasil. In: Bastos, Márcio Thomaz; Lopes, Carlos e Renault, Sérgio Rabello Tamm (Orgs.). Justiça Restaurativa: Coletânea de Artigos. Brasília: MJ e PNUD, 2005. Disponível em: www.justica21.org.br/interno.php? ativo=BIBLIOTECA Acesso em 29 jun 2021.

PINTO, R. S. G. A construção da justiça restaurativa no Brasil. Revista Paradigma, v. 1, n. 19, 4 nov. 2011.

PRUDENTE, Neemias Moretti; SABADELL, Ana Lucia. Mudança de paradigma: justiça restaurativa. In: Revista Jurídica Cesumar, v. 8, n. 1, p. 49-62, jan./jun. 2008. p. 49-62. Disponível em: https:// periodicos.unicesumar.edu.br/index.php/revjuridica/article/view/719. Acesso em 30 jun 2021

TIVERON, Raquel. Justiça restaurativa: a construção de um novo paradigma de justiça criminal. Brasília: Trampolim, 2017. E-book. 
ZEHR, Howard. Justiça restaurativa. - São Paulo: Palas Athena, 2015.

ZEHR, Howard. Trocando as lentes: justiça restaurativa para o nosso tempo. - São Paulo: Palas Athena, 2008. 